\title{
||||||||||||||||||||||||||||||||||||||||||||||||||||||||||||||||||.
}

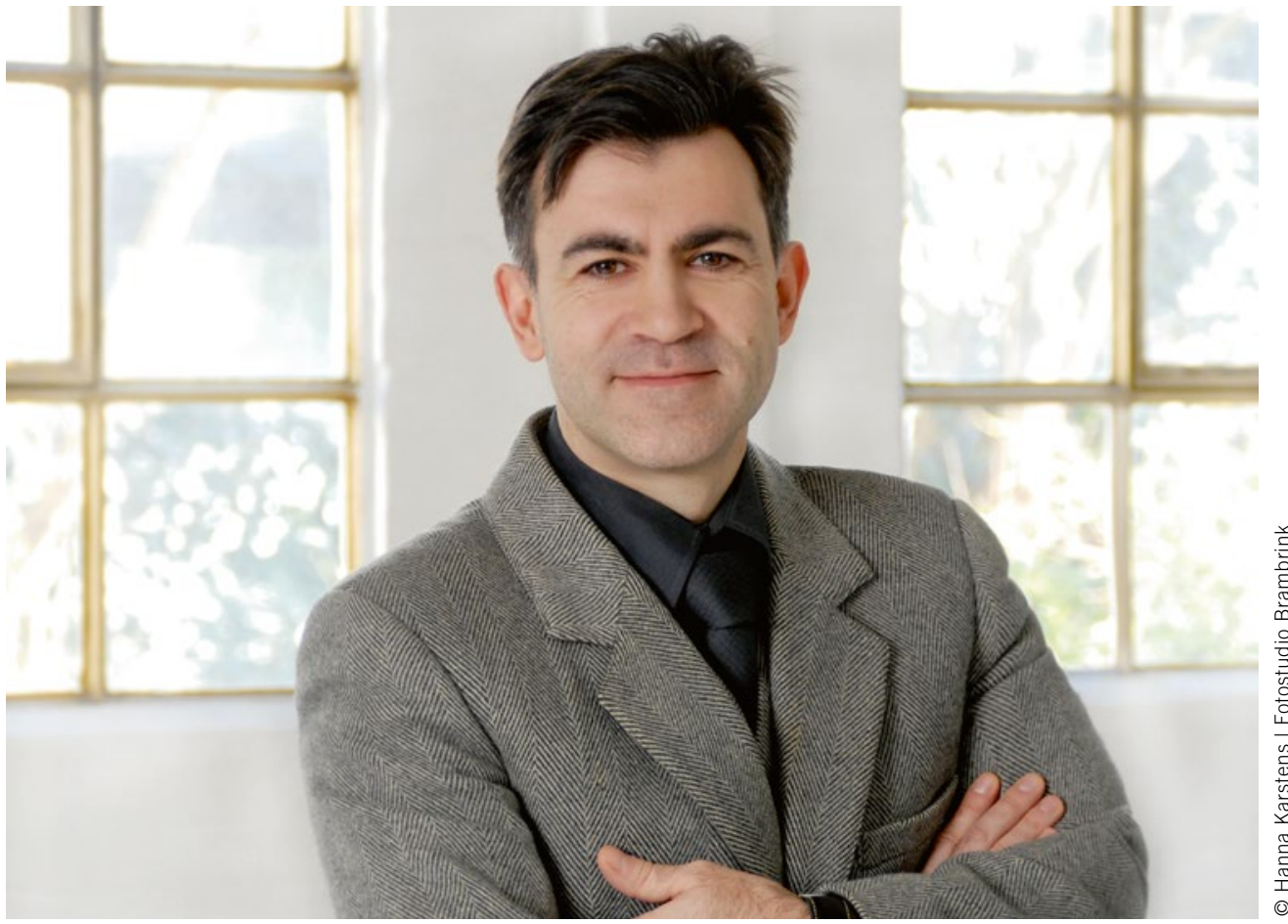

Prof. Alexander Piskun, M. Sc.

Professor für Karosseriekonstruktion und Datenverarbeitung, Department Fahrzeugtechnik und Flugzeugbau, Fakultät Technik und Informatik, HAW Hamburg

\section{Herausforderungen für die Karosserie}

Wir leben in bewegten Zeiten. Fast unscheinbar vollzieht sich durch Smartphones die Ablösung von Printmedien, die das Bild in Nahverkehrsmitteln dominiert haben. Ein moderner Scherz: Bei der Maslowschen Pyramide der menschlichen Bedürfnisse spricht man neuerdings von neuen Grundbedürfnissen: einer vollen Batterie und einer WLAN-Verbindung.

Dass die Fahrzeuggestalt sich in dieser Zeit ebenso stark verändert hat, fällt erst beim zweiten Blick auf. So brachte der Jahrtausendwechsel bullige Pkw-Frontends, markante Frontspoiler und höhere Motorhauben mit sich - ein Zugeständnis an den in Europa und Japan obligatorischen Fußgängerschutz.

Die Elektrifizierung des Antriebs dürfte die Gestalt der Karosserien stärker beeinflussen. Die sichere Batterieunterbringung im Fahrzeugboden erhöht die Insassenposition, die kompakteren Antriebe geben den Platzbedarf zugunsten des Gepäckraums frei. Das Tesla Model X zeigt prinzipiell schon heute auf, in welche Richtung sich die Karosserien der Elektroautos entwickeln werden. Eine Vielzahl von Derivaten treibt die Fahrzeughersteller dazu, Fahrzeugplattformen zu entwickeln, die die neue Fahrzeugarchitektur widerspiegeln. Aber nicht nur das Fahrzeugpackage ist betroffen: Die Antriebselektrifizierung ist mit einer Anpassung der Geräusch- und Wärmedämmung verbunden.

Die exponentiell steigende Technologieentwicklung wird zunehmend stärker durch die Elektronik- und Softwareentwicklung beeinflusst. Die kostenneutrale zweijährliche Ver- dopplung der Transistorendichte in einer integrierten Schaltung, auch als Mooresches Gesetz bekannt, treibt die Entwicklung der Assistenzen und Komfortmerkmale voran. So werden zum Beispiel 2018 hochintegrierte Radarsensoren in der Größe einer Streichholzschachtel aus Serienherstellung erwartet. Deren seitliche Positionierung würde einem Auto eine $360^{\circ}$ Pre-Crash-Sensorik bringen, aber auch die Möglichkeit, die Gesten von Passanten zu erfassen und zu deuten.

Die LED- und Lasertechnik sorgt einerseits für eine Entspannung des Scheinwerfermodul-Raumbedarfs im Frontend, andererseits ermöglicht sie ein interessantes Scheinwerferdesign „aus der Fuge“. Die Entwicklung der biegsamen OLED-Module kann zum einen das Heckleuchtendesign verbessern und zum anderen das Interieur eines Fahrzeugs aufwerten.

Insgesamt darf man in den kommenden Jahren publikumswirksame Erfolge jedoch primär von elektronischen Systemen erwarten, während sich die Veränderungen im Bereich der Karosserieentwicklung eher im Hintergrund abspielen. Die Aufgabenfülle, die die Herausforderung eines selbstfahrenden Fahrzeugs mit sich bringt, besitzt dagegen das Potenzial, unsere bisherigen Vorstellungen von einem Auto auf den Kopf zu stellen. Das Gute dabei: Die Faszination der Karosserieentwicklung wird nicht geringer. Ich freue mich vor diesem Hintergrund auf den Erfahrungsaustausch mit Ihnen auf den Hamburger Karosseriebautagen am 3. und 4. Mai 2017. 